\title{
Using DREADDs to isolate internal clocks
}

\section{Martilias S. Farrell*}

Department of Pharmacology, University of North Carolina School of Medicine, Chapel Hill, NC, USA

${ }^{*}$ Correspondence: martilias_farrell@med.unc.edu

Although much is known about the psychophysics of timing and time perception, the ability to selectively modulate discrete neuronal populations subserving interval timing could advance the field in unprecedented ways (see Buhusi and Meck, 2005; Allman and Meck, 2011; Cheng et al., 2011). Current approaches used to delineate the neuronal correlates of timing are often restricted to pharmacological (Meck, 1996; Coull et al., 2011) or ablative approaches, both physical (Meck, 2006a,b; Wiener et al., 2008) and genetic (Sysoeva et al., 2010; Agostino et al., 2011; Meck et al., 2011; Wiener et al., 2011). Most, if not all, of the ablative approaches are limited to loss of function-type hypothesis testing and frequently have unintended off-target effects. The pharmacologic approach has inherent confounds in the non-specificity of small molecule ligands. One way to overcome these confounds is to use a system in which a designer receptor exclusively activated by designer drug (DREADD) is expressed in a cell-type specific manner via transgenic expression. This chemicogenetic approach is further described by the acronym of the first tool of its type: receptor activated solely by synthetic ligand (RASSL). In short, a receptor is engineered such that it is no longer activated by any endogenous ligands and instead activated by an otherwise inert exogenous ligand. The various RASSLs and DREADDs have been reviewed elsewhere (Pei et al., 2008). In short, there are three DREADDs available with proven functionality in neuronal environments hM3Dq (Gq-coupled, promotes neuronal excitability), hM4Di (Gi-coupled, promotes neuronal inhibition), and the rM3Ds (Gs-coupled, promotes cAMP production). Here, we discuss this technology's potential in the field of interval timing.

Cell-type specificity of signaling has been a hurdle for delineating the neuroanatomical substrates of timing (Cheng et al., 2011). Using the chemicogenetic approach, it is possible to express a receptor in a select population of neurons and then turn that receptor on via peripheral administration of clozapine-N-oxide (CNO). The cell-type specificity is dependent upon the transgenic approach used, though the current genetic toolkit appears to be more than adequate for the study of interval timing. To date, there has been success expressing DREADDs using virally mediated approaches (Ferguson et al., 2011; Krashes et al., 2011; Sasaki et al., 2011), single-transgenic approaches (Guettier et al., 2009), and intersectional transgenic approaches (Alexander et al., 2009; Ray et al., 2011). With these approaches, it should be possible to place a DREADD into a subpopulation of neurons and then determine how this population modulates interval timing. Furthermore, the identical signaling-type initiated via the DREADDs in various subpopulations would allow us to piece together the circuitry by expressing the DREADD in multiple subpopulations either simultaneously or separately (Figure 1).

In addition to the cell-type specificity possible with DREADDs, this approach also affords us the ability to silently and independently modulate neuronal signaling. An inherent confound in the pharmacologic approach to neuronal modulation is the intrinsic interference with the endogenous tone of the system being investigated. By definition, any agonist interacting with a receptor competes with the endogenous ligand for that receptor. Thus, the experimental modulation is no longer limited to the modulation of the neuronal population induced by the ligand-receptor pair, but instead also includes interference in the homeostatic, basal signaling state of the system. As it is hypothesized that information is encoded in patterns of neuronal firing and the subsequent phasic neurotransmitter presence (Johnson, 2000), it can be seen that interfering with the temporal signaling nature of the basal state can be detrimental in our quest to determine the neuronal correlates of time (Figure 2). The DREADD overcomes this confound by the use of a non-native receptor which has no basal tone. Take, for example, the neurons of the striatum, a well renowned candidate for the epicenter of interval timing circuitry (Matell et al., 2003; Meck et al., 2008). In addition to the technical difficulty of selectively manipulating these neurons through pharmacological means (local microinjections), the key confound is that any pharmacological manipulation will interfere with the afferent tone on the striatal synapses (Figure 2B). Thus, the experimental manipulation is no longer limited to striatal medium spiny neuron (MSN) modulation, but instead now includes modulation of the afferent tone associated with the neurotransmitter of the targeted receptor. Thus, the experimental manipulation is affecting both the hypothetical integrator of information (the MSN) and the information itself (the phasic, temporally encoded presynaptic release of neurotransmitter). With the DREADD approach, it is possible to modulate the activity of the MSNs independent of the endogenous tone, leaving the theoretical temporally encoded information in place (Figure 2C). This provides us the unique opportunity to reductively piece together each component of the neuronal substrates of timing.

Finally, the usability of the chemicogenetic approach is another salient aspect when considering its application in the field of interval timing. Indeed, other approaches for cell-type specific control of neuronal signaling exist, most notably that of optogenetics (Yizhar et al., 2011). The optogenetic approach has many features that lend well to interval timing research - namely, the exclusive control of neuronal firing in the subsecond range. Both optogenetics and chemicogenetics achieve cell-type specific control of signaling through transgenic expression of a non-native receptor, so both approaches leave the endogenous tone intact. The chemicogenetic approach, in its simplest form (a single-transgenic mouse), requires a simple peritoneal injection of CNO to modulate cell-type specific neuronal signaling. This simplicity is an experimental aspect that cannot be ignored considering the exclusive use of behavior paradigms in the study of interval timing. 


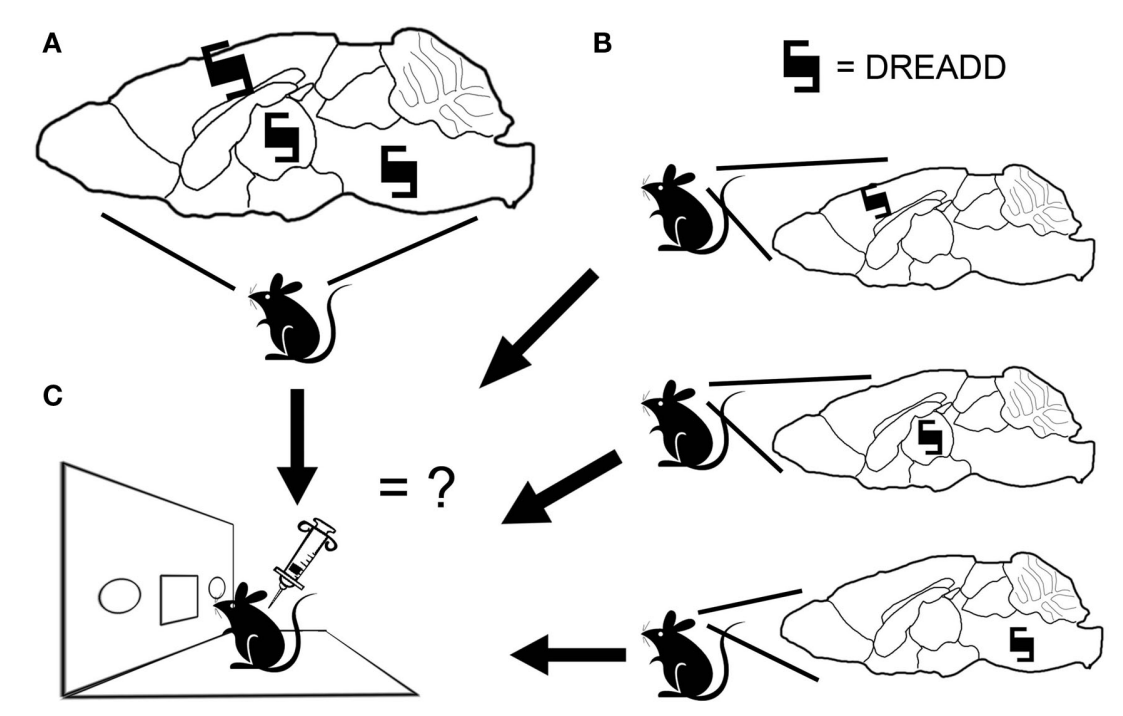

FIGURE 1 | Designer receptor exclusively activated by designer drug (DREADD) expression and behavior. (A) A DREADD can be expressed in multiple brain nuclei, permitting a global modulation of neuronal activity. (B) Alternatively, a DREADD can be placed in restricted cell populations. (C) By activating the DREADD via CNO injection and administering interval timing tests, it will be possible to compare the effect of selective neuronal modulation in different nuclei, or in multiple nuclei compared to individual nuclei, and thus determine the cell populations necessary for interval timing or sufficient to modulate these processes.
A Theoretical System

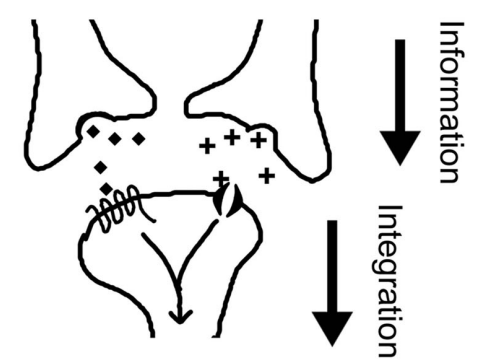

B Agonist-modulated system



FIGURE 2 |The benefit of non-invasive neuronal modulation. (A) A theoretical model for the neuronal correlate of interval timing, in which a post-synaptic neuron integrates information from multiple inputs. (B) In a classical pharmacological manipulation, an agonist is administered with the intent to modulate the post-synaptic neuron responsible for the integration of
C

DREADD-modulated system
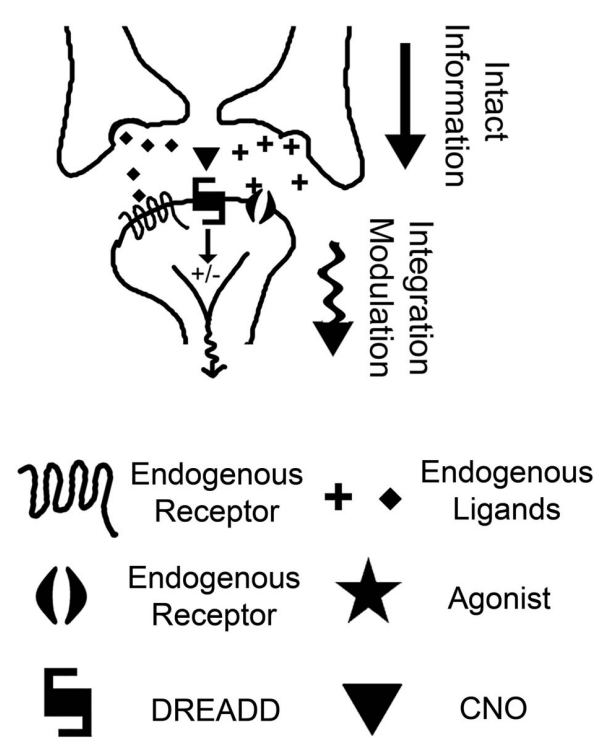

information. Instead, the agonist simultaneously interferes with the endogenous neurotransmitter tone, thus manipulating the information itself. (C) Using a DREADD, modulation of the post-synaptic neuron is achieved exclusively,

leaving the information intact. This allows direct investigation of the mechanisms of information integration.
In conclusion, it can be seen that by combining DREADDs and transgenic technology in the chemicogenetic approach it will be possible to further delineate the neuronal substrates of interval timing. The cell-type specific control in combination with the independent modulation of neuronal signaling afford a level of precision that is almost requisite in the investigation of such 
an intertwined neuronal process as that of interval timing. We propose an initial experiment here: investigating the functional role of the MSNs in temporal integration (see Matell and Meck, 2004; Oprisan and Buhusi, 2011). It can be seen that this technology is well suited for use in this field, and will hopefully advance our understanding of the neural basis of timing and time perception (Gibbon et al., 1997; Gu et al., 2011).

\section{REFERENCES}

Agostino, P.V., Golombek, D. A., and Meck, W.H. (2011). Unwinding the molecular basis of interval and circadian timing. Front. Integr. Neurosci. 5:64. doi: 10.3389/ fnint.2011.00064

Alexander, G. M., Rogan, S. C., Abbas, A. I., Armbruster, B. N., Pei, Y., Allen, J. A., Nonneman, R. J., Hartmann, J., Moy, S.S., Nicolelis, M. A., McNamara, J. O., and Roth, B. L. (2009). Remote control of neuronal activity in transgenic mice expressing evolved $G$ protein-coupled receptors. Neuron 63, 27-39.

Allman, M. J., and Meck, W.H. (2011). Pathophysiological distortions in time perception and timed performance. Brain. doi: 10.1093/brain/awr21

Buhusi, C. V., and Meck, W. H. (2005). What makes us tick? Functional and neural mechanisms of interval timing. Nat. Rev. Neurosci. 6, 755-765.

Cheng, R. K., Jesuthasan, S., and Penney, T. B. (2011). Time for zebrafish. Front. Integr. Neurosci. 5:40. doi: 10.3389/fnint.2011.00040

Coull, J. T., Cheng, R. K., and Meck, W. H. (2011). Neuroanatomical and neurochemical substrates of timing. Neuropsychopharmacology 36, 3-25.

Ferguson, S. M., Eskenazi, D., Ishikawa, M., Wanat, M. J., Phillips, P. E., Dong, Y., Roth, B. L., and Neumaier, J. F. (2011). Transient neuronal inhibition reveals opposing roles of indirect and direct pathways in sensitization. Nat. Neurosci. 14, 22-24.

Gibbon, J., Malapani, C., Dale, C. L., and Gallistel, C. (1997). Toward a neurobiology of temporal cogni- tion: advances and challenges. Curr. Opin. Neurobiol. 7, 170-184.

Gu, B. M., Cheng, R. K., Yin, B., and Meck, W. H. (2011). Quinpirole-induced sensitization to noisy/sparse periodic input: temporal synchronization as a component of obsessive-compulsive disorder. Neuroscience 179, 143-150.

Guettier, J. M., Gautam, D., Scarselli, M., de Azua, I. R., Li, J. H., Rosemond, E., Ma, X., Gonzalez, F. J., Armbruster, B. N., Lu, H., Roth, B. L., and Wess, J. (2009). A chemical-genetic approach to study G protein regulation of beta cell function in vivo. Proc. Natl. Acad. Sci. U.S.A. 106, 19197-19202.

Johnson, K. O. (2000). Neural coding. Neuron 26, 563-566. Krashes, M. J., Koda, S., Ye, C., Rogan, S. C., Adams, A. C., Cusher, D. S., Maratos-Flier, E., Roth, B. L., and Lowell, B. B. (2011). Rapid, reversible activation of AgRP neurons drives feeding behavior in mice. J. Clin. Invest. 121, 1424-1428.

Matell, M. S., and Meck, W. H. (2004). Cortico-striatal circuits and interval timing: coincidence detection of oscillatory processes. Cogn. Brain Res. 21, 139-170.

Matell, M. S., Meck, W. H., and Nicolelis, M.A. L. (2003). Interval timing and the encoding of signal duration by ensembles of cortical and striatal neurons. Behav. Neurosci. 117, 760-773.

Meck, W. H. (1996). Neuropharmacology of timing and time perception. Cogn. Brain Res. 3, 227-242.

Meck, W.H. (2006a). Frontal cortex lesions eliminate the clock speed effect of dopaminergic drugs on interval timing. Brain Res. 1108, 157-167.

Meck, W.H. (2006b). Neuroanatomical localization of an internal clock: a functional link between mesolimbic, nigrostriatal, and mesocortical dopaminergic systems. Brain Res. 1109, 93-107.

Meck, W.H., Cheng, R. K., Macdonald, C. J., Gainetdinov, R. R., Caron, M. G., and Cevik, M. O. (2011). Genedose dependent effects of methamphetamine on interval timing in dopamine-transporter knockout mice. Neuropharmacology. doi: 10.1016.j.neuroph arm.2011.01.042. [Epub ahead of print].

Meck, W. H., Penney, T. B., and Pouthas, V. (2008). Cortico-striatal representation of time in animals and humans. Curr. Opin. Neurobiol. 18, 145-152.
Oprisan, S. A., and Buhusi, C. V. (2011). Modeling pharmacological clock and memory patterns of interval timing in a striatal beat-frequency model with realistic, noisy neurons. Front. Integr. Neurosci. 5:52. doi: 10.3389/fnint.2011.00052

Pei, Y., Rogan, S. C., Yan, F., and Roth, B. L. (2008). Engineered GPCRs as tools to modulate signal transduction. Physiology 23, 313-321.

Ray, R. S., Corcoran, A. E., Brust, R. D., Kim, J. C., Richerson, G. B., Nattie, E., and Dymecki, S. M. (2011). Impaired respiratory and body temperature control upon acute serotonergic neuron inhibition. Science 333, 637-642.

Sasaki, K., Suzuki, M., Mieda, M., Tsujino, N., Roth, B., and Sakurai, T. (2011). Pharmacogenetic modulation of orexin neurons alters sleep/wakefulness states in mice. PLoS ONE 6, e20360. doi: 10.1371/journal. pone. 0020360

Sysoeva, O. V., Tonevitsky, A. G., and Wackermann, J. (2010). Genetic determinants of time perception mediated by the serotonergic system. PLOS ONE 5, e12650. doi: 10.1371/journal.pone.0012650

Wiener, M., Lohoff, F. W., and Coslett, H. B. (2011). Double dissociation of dopamine genes and timing in humans. J. Cogn. Neurosci. 23, 2811-2821.

Wiener, M., Magaro, C. M., and Matell, M. S. (2008). Accurate timing but increased impulsivity following excitotoxic lesions of the subthalamic nucleus. Neurosci. Lett. 440, 176-180.

Yizhar, O., Fenno, L. E., Davidson, T. J., Mogri, M., and Deisseroth, K. (2011). Optogenetics in neural systems. Neuron 71, 9-34.

Received: 01 December 2011; accepted: 02 December 2011; published online: 23 December 2011.

Citation: Farrell MS (2011) Using DREADDs to isolate internal clocks. Front. Integr. Neurosci. 5:87. doi: 10.3389/ fnint.2011.00087

Copyright (c) 2011 Farrell. This is an open-access article distributed under the terms of the Creative Commons Attribution Non Commercial License, which permits non-commercial use, distribution, and reproduction in other forums, provided the original authors and source are credited. 